\title{
La tecnología de la información en la formación bibliotecológica
}



n las úl timas dos dé ca das, a nivel mun dial, la tec no lo gía y las te le comunicaciones sehandesarrolladomuchoymodificadolas actividades laborales de muchas personas, profesionales y no profesionales, así como desaparecido algunas actividades, optimizado otras y creado nuevas.

El uso de la computadora se ha generalizado de tal forma que ahora no se puede concebir el área de servicios administrativos, públicos o financieros sin una máquina que apoye esas actividades, por lo que el conocimiento de tipos de computadora, procesadores de palabra, hojas de cálculo, bases de datos, etcétera, se ha convertidoenunanecesidadimprescindibleparamantenerseac tualiza do y para la cual sehan di seña do innumerables cursos, talleres, escuelas y hasta nuevas licenciaturas.

Enelgremiobibliotecarioestedesarrollo tecnológiconohapasa do desapercibido, por lo que su influencia se ha dejado sen tiren prime rains tancia en el ejercicio profesional y también en la educación bibliotecológica.

En el ejercicio profesional el uso de programas y sistemas de automatización para bibliotecas se ha convertido en un requerimiento básico para satisfacer las necesidades de información de los usuarios, tanto así que para elegir el sistema adecuado, conocer sus ventajas, desventajas y su al can ce, el pro fe sio nal de la bi bliotecología se ha visto inmerso en una dinámica de actualización profesional que lo ayude a obtener los conocimientos que durante su formación no le fueron proporcionados. Ante esta situación, las escuelas debibliotecologíahanrespondido modificando sus programas de estudio, e introducido materias, programaseinclu soáreas de tec nología delain for mación, y cambiado nombres deactividadesy has tadeprofe sionales. Peropodríamos preguntarnos sinues tro obje to dees tudiohacambiado, sinues troobjetivo final(la sa tis fac cióndelas necesidades de información) se ha modificado y si los conocimientos básicos disciplinarios se han transformado con el uso de las computadoras. 
Como profesionales de la bibliotecología, el manejo y administración de la información a través de sus diferentes recursos ha sido el objeto de estudio desde que se creó la escritura y el hombre se decidió a preservar la información dibujada y luego escrita en un material escriptóreo. La satisfacción de las necesidades de información de los usuarios se convirtió en una de nuestras principales funcio nes des de quese abrie ron las puer tas delas biblio te cas a las comunidades, y estos preceptos se han venidousandocomoelementos básicos de la formación de los profesionales del área bibliotecológica a través de sus principales áreas disciplinarias:organizaciónbibliográficaydocumental; recursos de información documental; administración de las unidades y sistemas de información documental; y servicios bibliotecariosy de información,sustentado todo en un conjunto de conocimientos teóricos básicos de la disciplina y la metodología de investigación apropiada para generar nuevos conocimientos. Todo ello es la base que permiteundesarrollo y ejercicio profesional bibliotecario de calidad, independientemente de la tecnología que se use.

Pero el uso de la tecnología actual, el uso de telecomunicaciones para romper con las barre ras de dis tan cia y tiem poen tre quienes gene rany tie nen lain forma ción y quienes la requieren, sí implica un cambio sustancial en el perfil bibliotecológico, lo cual no tiene que ver con los nombres ni con las actividades. Se requieredeuncambio deactitud, se re quieredepro fe sionales delabibliotecología que tengan creatividad, iniciativa, imaginación, espíritu innovador y ánimo positivo para asumir los cambios y ser capaces de optimizar los recursos disponibles para proporcionar servicios pertinentes, eficientes y eficaces.

Es tos cam bios de ac titudantela pro fe sión permitiránel re dimen sionamien to de la misma y la asimilación de la tecnología de la información como una herramienta indispensable que se debe conocer y ser siempre un apoyo para la actividad bibliotecaria pero nuncaun sus titu to delbibliotecólogo, al guienque está más allá de la búsqueda y recuperación mecánica de la información.

\section{Lina Escalona Ríos}

